\title{
En mann i 60-årene med tungpust og hypoksemi
}

Utredning av tungpust er en vanlig, men av og til utfordrende problemstilling både i allmennpraksis og ved indremedisinske poliklinikker og avdelinger. Denne sykehistorien viser at utredningen kan være komplisert og at samarbeid mellom ulike spesialiteter er nyttig.

Se kommentar side 191 og kunnskapsprøve på www.tidsskriftet.no/quiz

En mann i 60-årene ble vurdert ved lungepoliklinikken på et lokalsykehus etter at han de siste to-tre måneder hadde hatt betydelig tungpust, både ved anstrengelse og i hvile. Grunnet tendens til ankelødemer hadde han brukt vanndrivende medisiner en tid forut for konsultasjonen. For øvrig brukte han ingen faste medisiner. Han var tidligere stort sett frisk, bortsett fra en episode med mulig «treskerlunge» (hypersensitivitetspneumonitt) med full tilbakegang.

Klinisk undersøkelse avdekket hviledyspné, leppe- og neglesengcyanose. Lungeauskultasjon var upåfallende. Det hørtes en systolisk bilyd grad 2/6, andre interkostalrom parasternalt venstre side. Blodgass uten oksygentilskudd viste uttalt hypoksemi med $\mathrm{pO}_{2}$ $7,11 \mathrm{kPa}, \mathrm{pCO}_{2} 4,1 \mathrm{kPa}, \mathrm{pH} 7,44$ og $\mathrm{O}_{2}$-saturasjon $88 \%$. Fingeroksymetri viste $85 \%$ $( \pm 4 \%)$ i ro og ved lett bevegelse på pasientrom over tid, uten signifikant endring ved $\mathrm{O}_{2}$-tilførsel gjennom nese-brille-kateter titrert opp til $4 \mathrm{l} \mathrm{O}_{2} / \mathrm{min}$. Røntgen thorax og EKG var normale. Spirometriundersøkelsen var normal med forsert vitalkapasitet (FVK) 6,4 ( (124\% av forventet), forsert ekspiratorisk volum etter ett sekund $\left(F E V_{1}\right)$ 4,0 l (100\% av forventet). Diffusjonstest (CO) var normal med transferfaktor for karbonmonoksid (DLCO) $80 \%$ av forventet. Høyoppløsnings-CT (HRCT) viste spredte emfysemblærer og noen bronkiektasier.

Selv om pasienten var tidligere røyker og høyoppløsnings-CT viste beskjedne tegn til emfysemblærer og bronkiektasier, taler normale lungefunksjonsundersøkelser imot betydelig lungeparenkym- eller luftveissykdom som årsak til såpass uttalt hypoksemi. Idiopatisk eller familiær pulmonal arteriell hypertensjon og pulmonal arteriell hypertensjon assosiert med bindevevssykdommer kan gi hypoksemi, men det vil da forventes reduksjon i diffusjonskapasiteten (1). Lungeemboli ble utelukket med $\mathrm{CT}$ av lungearterier og ventilasjons-perfusjons-skanning. Cyanotisk hjertefeil er en differensialdiagnose som man kunne avklare med ultralydundersøkelse av hjertet.
Pasienten ble henvist fra lokalsykehus til lungeavdelingen ved St. Olavs hospital. På grunn av uavklarte funn ved ultralyd av hjertet utført ved lokalsykehus ble det henvist til fornyet ultralydundersøkelse som viste venstre ventrikkel med normale dimensjoner og funksjon. Høyre hjertehalvdel var hyperdynamisk og dilatert. Det var stor lekkasje over trikuspidalklaffen og noe mindre over pulmonalklaffen. Det var tegn til økt trykk i høyre atrium, og det ble estimert et moderat forhøyet systolisk lungearterietrykk på $50 \mathrm{~mm} \mathrm{Hg}$.

Siden hypoksemien kunne være utrykk for at blodet ble shuntet fra venøst til systemisk kretsløp, ble det injisert agitert saltvannsoppløsning (luftmikrobobler) i perifer vene. Umiddelbar påvisning av «kontrast» $i$ venstre atrium antydet at det var en stor kontrastpassasje på forkammernivå (fig 1). En slik shunting av venøst blod til venstre hjertekammer kunne forklare pasientens hypoksemi og tungpust. For å kartlegge årsaksforholdene nærmere ble det utført transøsofageal ekkokardiografi da denne metoden gir høyere bildeoppløsning. Undersøkelsen avdekket et åpent (patent) foramen ovale (fig 2).

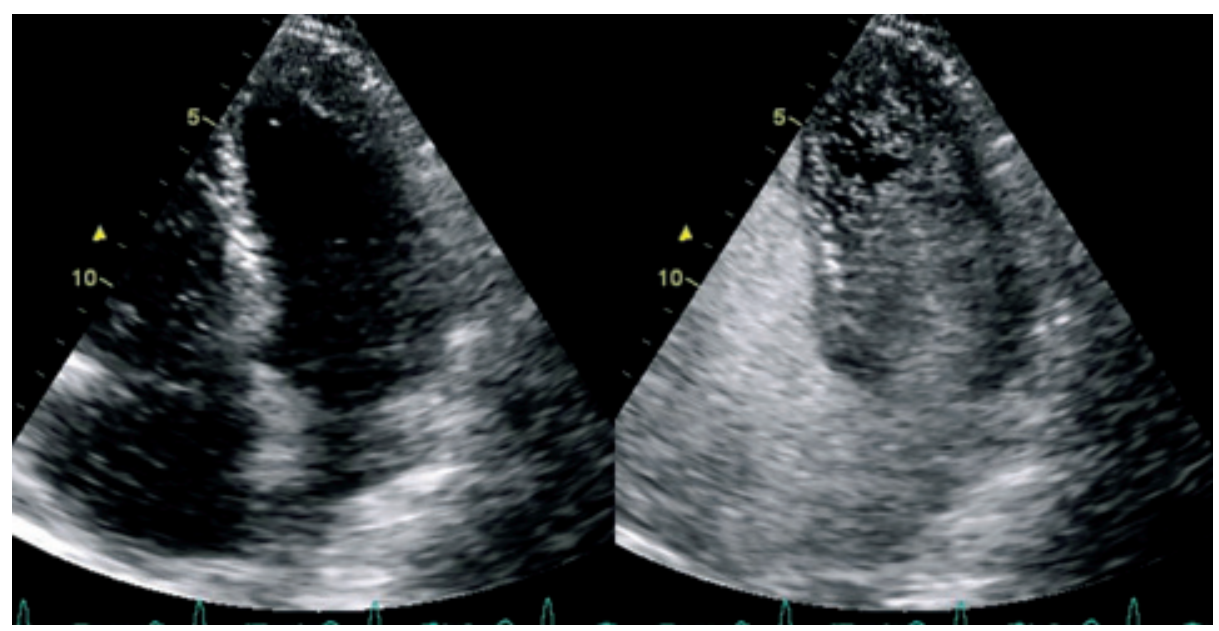

Figur 1 Firekammerbilder umiddelbart etter injeksjon av agitert saltvann. Stor passasje av luftmikrobobler mellom høyre og venstre hjertehalvdel gir lys ventrikkelkavitet i bildet til høyre tet ga mistanke om karsinoid hjertesykdom.
Hyppigheten av åpent foramen ovale i normalbefolkningen er 25-30\% $(2,3)$. Ved normale trykkforhold $\mathrm{i}$ hjertet vil åpent foramen ovale ikke medføre betydelig grad av shunting av venøst blod (4). Vår pasient hadde flere ekkokardiografiske tegn på trykk-volum-belastning av høyre hjertehalvdel: venestuving, dilatert v. cava, V-bølge, bukende atrieseptum og høye antegrade hastigheter over trikuspidalostiet. Derfor ønsket man bedre visualisering av trikuspidalklaffen.

I en noe uortodoks projeksjon fremkom det at trikuspidalinsuffiensen var stor (grad 3-4/4). Trikuspidalklaffens seil var fortykket, korte og lite mobile. Klaffeseilene sto $i$ halvåpen posisjon i systolen når de skulle være lukket. De påviste forandringene i trikuspidalapparaVed å plassere ultralydhodet under kostalbuen kunne leveren visualiseres. Leveren var inhomogen med multiple ekkotette lesjoner, slik at mistanken om karsinoid sykdom ble ytterligere forsterket (fig 3).

Karsinoide avleiringer på trikuspidalseilene hadde medført progredierende trikuspidalinsuffisiens. Dette førte videre til økt trykk i atriet med stor shunting av blod gjennom det åpenstående foramen ovale. Pulmonalklaffen, aortaklaffen og mitralklaffen hadde kun mindre insuffisienser, uten tegn til karsinoide forandringer. Karsinoide tumorer kan produsere en rekke ulike substanser, bl.a. serotonin som er sentralt i patogenesen ved karsinoid hjertesykdom. Serotonin aktiverer myofibroblaster som lager karakteristiske 


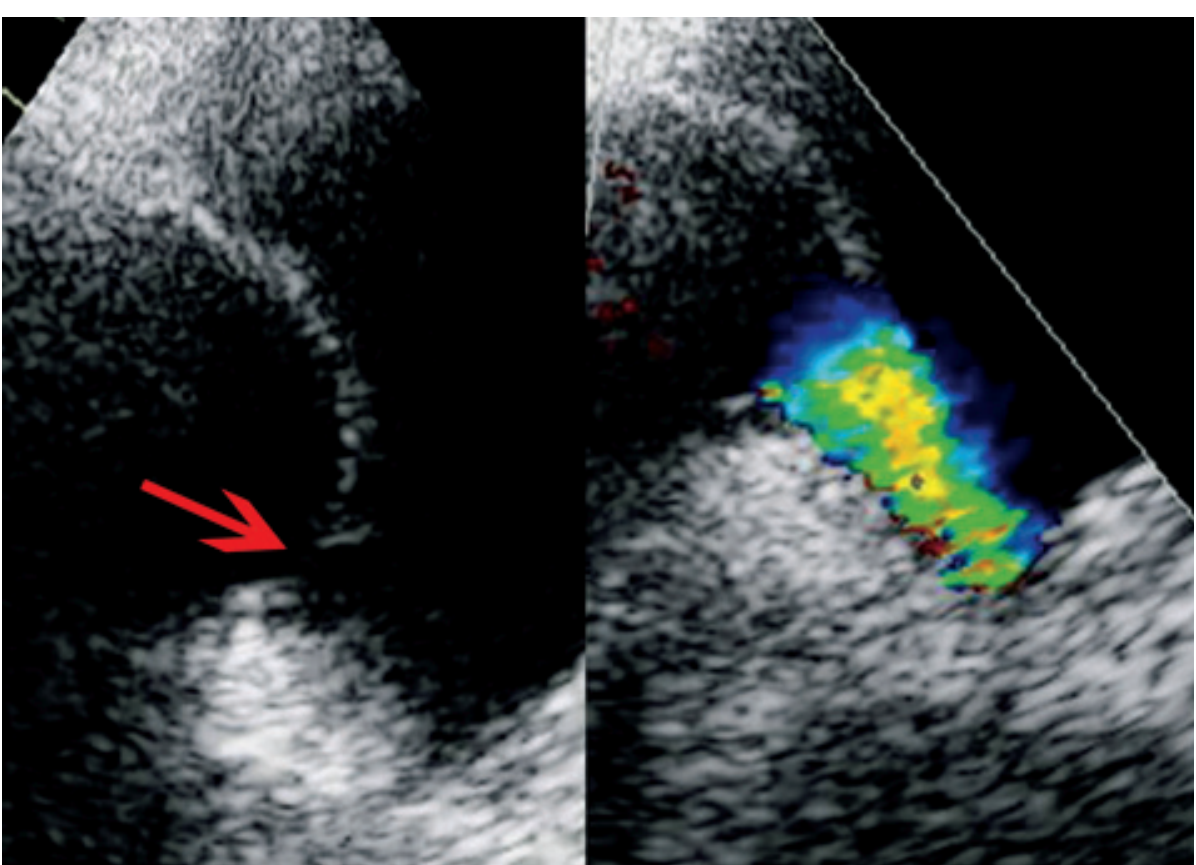

Figur 2 Transøsofageale stillbilder viser stort foramen ovale (pill) med strøm mellom høyre og venstre atrium

kollagenavleiringer i hjertets klaffeapparat $(5,6)$. Da serotonin inaktiveres i pulmonalkretsløpet, rammes hyppigst det høyresidige klaffeapparatet, og trikuspidalklaffen affiseres hyppigere enn pulmonalklaffen. Affeksjon av det venstresidige klaffeapparatet er mer sjeldent, og er assosiert med åpent foramen ovale, bronkial karsinoid eller utbredt metastasering $(6,7)$.

Diagnosen karsinoid sykdom ble bekreftet med CT abdomen, skyhøye serotoninmetabolitter i urin, 5-hydroksyindoleddiksyre (U5-HIAA) $1400 \mu \mathrm{mol} / \mathrm{l}$, kraftig forhøyet kromogranin-A (s-CgA $367 \mathrm{nmol} / \mathrm{l})$ og oktreotid

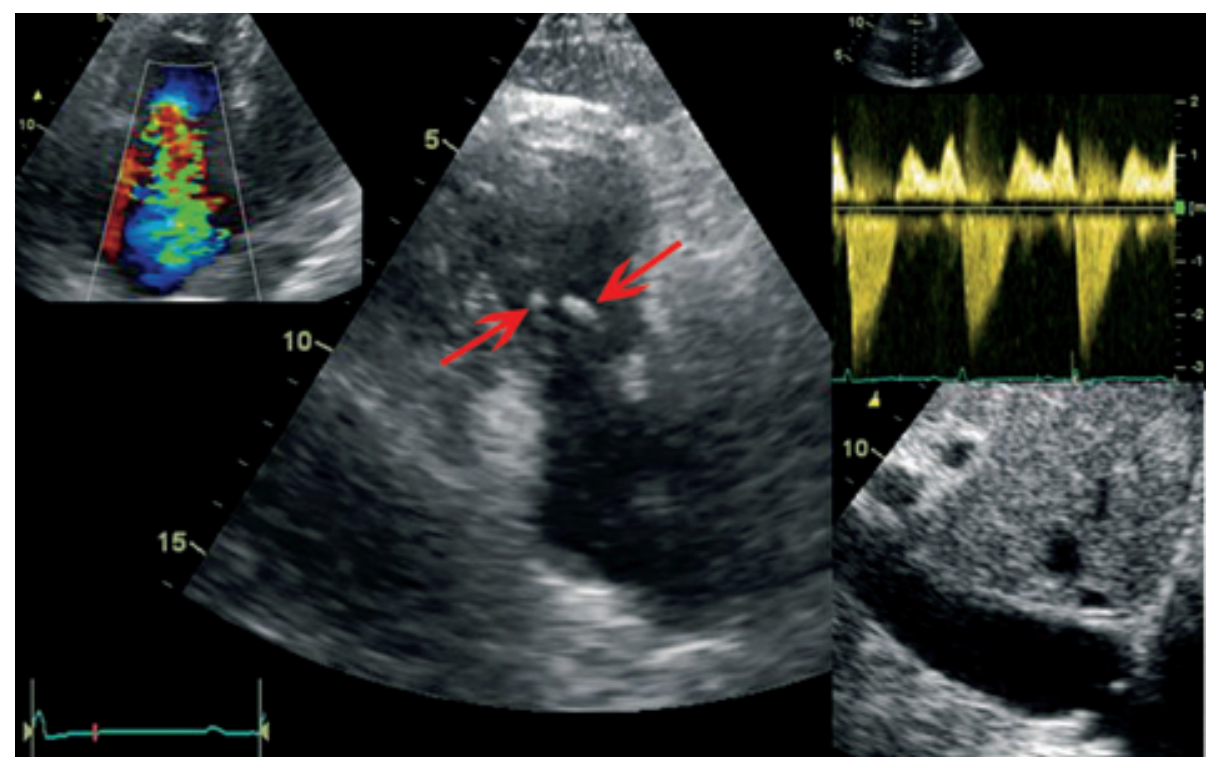

Figur 3 Fargedoppler av stor trikuspidalinsuffisiens. Trikuspidalklaff med fortykkede, forkortede, lite mobile seil som står i åpen posisjon i systolen (piler). Kontinuerlig doppler av trikuspidalinsuffisiens med makshastighet $2,8 \mathrm{~m} / \mathrm{s}$ og V-bølge. Inhomogen lever med dilatert v. cava uten inspiratorisk diameterreduksjon grep med implantasjon av biologisk trikuspidalventil og aortokoronar bypass, samt suturering av åpent foramen ovale. Det postoperative forløpet var ukomplisert og pasientens hypoksemi og dyspnésymptomer bedret seg raskt. Kort tid etter det hjertekirurgiske inngrepet var pasienten i vesentlig bedre form enn forut for inngrepet, og ca. fire måneder senere ble det utført reseksjon av karsinoid tumor i distale ileum. Pasienten er nå i god form og det er videre planlagt leverembolisering og eventuell kjemoterapi senere.

\section{Diskusjon}

I en studie basert på Kreftregisteret, som Hauso og medarbeidere nylig har presentert, er insidensen av nevroendokrine svulster i Norge 3-4/100 000/år (8). Ca. $50 \%$ av pasienter med karsinoid syndrom utvikler karsinoid hjertesykdom. Høye nivåer av U-5-HIAA, kardial affeksjon og spesielt høyresidig hjertesvikt er assosiert med dårlig prognose $(6,7)$. Moderne behandling (inkludert hjertekirurgi) har bedret prognosen betydelig ved karsinoid hjertesykdom. I et materiale fra Mayo-klinikken er det observert økt median overlevelse fra 1,5 år til 7,1 år i løpet av siste to tiår (9). Det er uvanlig at diagnosen karsinoid syndrom stilles på bakgrunn av hypoksemiutredning og funn ved ultralydundersøkelse av hjertet. Ved erkjent karsinoid syndrom er derimot kombinasjonen karsinoid hjertesykdom og shunt gjennom åpent foramen ovale relativt hyppig omtalt $\mathrm{i}$ litteraturen. I en prospektiv studie av 54 pasienter med karsinoid hjertesykdom fikk hele $41 \%$ påvist åpent foramen ovale, noe som var signifikant høyere forekomst enn i kontrollgruppen (10). Kombinasjonen karsinoid hjertesykdom og åpent foramen ovale er assosiert med dårlig prognose bl.a. pga. fare for utvikling av venstresidig hjertesykdom. Det anbefales lukking av symptomgivende åpent foramen ovale $\mathrm{i}$ denne populasjonen. Derfor vil vi anbefale at det undersøkes om pasienter med karsinoid hjertesykdom har et åpent foramen ovale. Samtidig vil vi minne om at karsinoid hjertesykdom er en differensialdiagnose ved høyresidig hjertesvikt og at åpent foramen ovale kan gi hypoksemi ved samtidig volumbelastning av høyre atrium.

Utredning og behandling stilte krav til samarbeid og god koordinering på tvers av spesialistgrensene. Vår pasient hadde åpenbar nytte av vurdering av flere subspesialister innenfor indremedisin, kirurgi og onkologi, med til dels høyspesialisert kompetanse. Likevel var utgangspunktet en vanlig problemstilling - dyspné - og helhetstenkning og bred utredning var nødvendig for å komme frem til riktig diagnose. 


\section{Anders Thorstensen}

anders.thorstensen@ntnu.no

Klinikk for hjertemedisin

St. Olavs hospital

7006 Trondheim

Institutt for sirkulasjon og bildediagnostikk

Norges teknisk-naturvitenskapelige universitet

Tore Amundsen

Avdeling for lunge- og arbeidsmedisin

St. Olavs hospital

\section{Constantin Jianu}

Avdeling for fordøyelses- og leversykdommer

St. Olavs hospital

Jan S. Vilsvik

Medisinsk avdeling

Sykehuset Innlandet, Tynset

\section{Johannes Soma}

Klinikk for hjertemedisin

St. Olavs hospital
Pasienten har gitt samtykke til at artikkelen blir publisert.

Oppgitte interessekonflikter: Ingen

\section{Litteratur}

1. Simonneau G, Galie N, Rubin LJ et al. Clinical classification of pulmonary hypertension. J Am Coll Cardiol Suppl 2004; 43: 5-12.

2. Hagen PT, Scholz DG, Edwards WD. Incidence and size of patent foramen ovale during the first 10 decades of life: an autopsy study of 965 normal hearts. Mayo Clin Proc 1984; 59: 17-20.

3. Meissner I, Whisnant JP, Khandheria BK et al. Prevalence of potential risk factors for stroke assessed by transesophageal echocardiography and carotid ultrasonography: the SPARC study. Stroke prevention: assessment of risk in a community. Mayo Clin Proc 1999; 74: 862-9.

4. Pinto FJ. When and how to diagnose patent foramen ovale. Heart 2005: 91: 438-40.

5. Gustafsson BI, Tommeras K, Nordrum I et al. Long term serotonin administration induces heart valve disease in rats. Circulation 2005; 111: 1517-22.
6. Gustafsson B, Hauso $\emptyset$, Kidd M et al. Carcinoid heart disease. I: Modlin IM, Øberg K, red. A century of advances in neuroendocrine tumor biology and treatment. Hannover: Felsenstein C.C.C.P., 2008: 288-97.

7. Bernheim AM, Connolly HM, Hobday TJ et al. Carcinoid heart disease. Prog Cardiovasc Dis 2007; 49 439-51.

8. Hauso $\emptyset$, Gustavsson BI, Kidd M et al. Neuroendocrine tumor epidemiology: contrasting Norway and North America. Cancer 2008; 113: 2655-64.

9. Moller J, Pellikka PA, Bernheim AM et al. Prognosis of carcinoid heart disease: analysis of 200 cases over two decades. Circulation 2005; 112 $3320-7$.

10. Mansencal N, Mitry E, Pillière R et al. Prevalence of patent foramen ovale and usefulness of percutaneous closure device in carcinoid heart disease. Am J Cardiol 2008; 101: 1035-8.

Manuskriptet ble mottatt 30.4. 2008 og godkjent

15.11. 2008. Medisinsk redaktør Odd Terje

Brustugun.

\section{Kommentar}

\section{Hjertesykdom med sjelden årsak}

Karsinoid hjertesykdom er en komplikasjon til nevroendokrine svulster, særlig de som oppstår i tynntarmen. Pasienter med karsinoid hjertesykdom har ofte utbredte levermetastaser og samtidig det «karsinoide syndrom» forårsaket av tumorproduserte sirkulerende vasoaktive substanser som serotonin, takykiner og bradykiner (1). Karsinoid hjertesykdom oppstår hos $35-70 \%$ av pasienter med karsinoid syndrom $(2,3)$, og er karakterisert av plakkliknende fibrotiske subendotellesjoner (1). Lesjonene fører til endokardial fortykkelse både i veggen og i klaffene, med retraksjon og fiksering av klaffene som følge. Dette kan så lede til hjertesvikt med behov for klaffekirurgi. I over $90 \%$ av tilfellene foreligger det kun affeksjon av hjertets høyre side, sannsynligvis sekundært til metabolisme av vasoaktive tumorprodukter mens de passerer igjennom det lille kretsløpet, noe som beskytter hjertets venstre side fra eksponering. Venstresidig affeksjon oppstår når det finnes intrakardial shunting som ved et åpentstående foramen ovale. Venstresidig affeksjon kan også oppstå ved bronkialt karsinoid og hos pasienter med dårlig kontrollert karsinoid syndrom og derav meget høyt sirkulerende serotoninnivå som overgår lungenes kapasitet til å nedbryte vasoaktive substanser (1).

Patogenesen bak karsinoid hjertesykdom er fortsatt uklar. Serotonin spiller trolig en viktig rolle. Flere studier har demonstrert høye nivåer av 5-hydroksyindoleddiksyre, en metabolitt av serotonin, i urin hos pasienter med karsinoid hjertesykdom. Medikamenter med serotoninliknende struktur, eksempelvis fenfluramin, fører til lesjoner som er nesten identiske med dem man ser ved karsinoid hjertesykdom. Det er også vist at intravenøs tilførsel av serotonin til rotter resulterer i histologiske forandringer som lik- ner på karsinoid hjertesykdom (4). Behandling med somatostatinanaloger, som reduserer sirkulerende nivåer av serotonin, hindrer likevel ikke alltid utvikling eller progrediering av karsinoid hjertesykdom. Cytokiner og vekstfaktorer som er involvert $i$ andre fibrotiske tilstander spiller muligens en rolle, men dette er fortsatt uavklart.

Pasienter med karsinoid hjerteaffeksjon har dårligere overlevelse enn pasienter uten denne komplikasjonen. Men som dokumentert $\mathrm{i}$ artikkelen, har prognosen blitt bedre over de siste 20 årene. Den forbedrede prognosen er til dels et resultat av hyppigere og tidligere klaffekirurgi (5), men man spekulerer på om økt bruk av behandling som reduserer sirkulerende vasoaktive substanser, som for eksempel somatostatinanaloger eller leverarterieembolisering, også har bidratt.

Grunnet ofte uspesifikke allmennplager, som for eksempel diaré, blir pasienter med nevroendokrine svulster i tynntarmen ofte diagnostisert $i$ et sent stadium. Det er sjelden at karsinoid hjerteaffeksjon er første presentasjon av sykdommen. Det er fortsatt uenighet om på hvilket tidspunkt man skal utføre ekkokardiografi hos pasienter med nevroendokrine svulster i tynntarmen. I det minste bør alle med en hørbar bilyd og/eller symptomutvikling som kan tyde på hjerteaffeksjon henvises til ekkokardiografi.

Hos pasienter med karsinoid hjertesykdom og alvorlig affeksjon av høyre hjertehalvdel kan det oppstå økt høyre-til-venstreshunting gjennom et åpentstående foramen ovale på grunn av økt trykk i høyre atrium. Teoretisk sett kan dette øke faren for venstresidig affeksjon. Forfatterne foreslår at pasienter med karsinoid hjerteaffeksjon undersøkes for åpent foramen ovale, men per i dag finnes det ingen formelle retningslinjer for dette. Imidlertid kan det være god grunn til en slik vurdering når det er tegn på venstresidig affeksjon, eller det foreligger symptomer som kan tyde på shunting, for eksempel hypoksi, cyanose eller perifere systemiske embolier. Undersøkelse for åpent foramen ovale bør i tillegg vurderes hos alle pasienter som skal opereres for karsinoid hjerteaffeksjon. Som anbefalt i denne aktuelle artikkelen kan lukking av et symptomgivende åpent foramen ovale gjøres samtidig med klaffekirurgi, dette vil forbedre symptomer samt beskytte mot fremtidig venstresidig affeksjon.

\section{Deidi Ann Bergestuen}

deidi.bergestuen@rikshospitalet.no

Medisinsk avdeling

Rikshospitalet

0027 Oslo

\section{Svend Aakhus}

Hjertemedisinsk avdeling

Rikshospitalet

\section{Oppgitte interessekonflikter: Ingen}

\section{Litteratur}

1. Connolly HM, Pellikka PA. Carcinoid heart disease Curr Cardiol Rep 2006; 8: 96-101.

2 Denney WD Kemp WE jr. Anthony LB et al. Echocardiographic and biochemical evaluation of the development and progression of carcinoid heart disease. J Am Coll Cardiol 1998; 32: 1017-22.

3. Moller JE, Connolly HM, Rubin J et al. Factors associated with progression of carcinoid heart disease. N Engl J Med 2003; 348: 1005-15.

4. Gustafsson BI, Tommeras K, Nordrum I et al. Long term serotonin administration induces heart valve disease in rats. Circulation 2005: 111: 1517-22.

5. Moller JE, Pellikka PA, Bernheim AM et al. Prognosis of carcinoid heart disease: analysis of 200 cases over two decades. Circulation 2005; 112: $3320-27$ 